\title{
RESEARCH
}

\section{OUTCOMES OF ELDERLY PATIENTS UNDERGOING CARDIOPULMONARY RESUSCITATION IN THE EMERGENCY DEPARTMENT: A 7-YEAR ANALYSIS ABSTRACT}

DOI: $10.31086 /$ tigeri.2020.170

2020; 23(3): 334-341

\section{- Afşın IPEKCi 1 (D) \\ - Fatih ÇAKMAK ${ }^{1}$ (D) \\ - Serap BIBEROǦLU' (D \\ - Yonca Senem AKDENIZ1 1 D \\ - Seda ÖZKAN ${ }^{1}$ (D) \\ - ibrahim IKIZCELi' 1 D}

CORRESPONDANCE

\section{Afşın IPEKCI}

Istanbul University-Cerrahpasa, Cerrahpasa

Faculty of Medicine, Department of Emergency

Medicine, Istanbul, Turkey

Phone: +902124143000

e-mail: afsin.ipekci@istanbul.edu.tr

Received: Apr 29, 2020

Accepted: Jul 26, 2020

1 Istanbul University-Cerrahpasa, Cerrahpasa Faculty of Medicine, Department of

Emergency Medicine, Istanbul, Turkey

\section{Abstract}

Introduction: We aimed to analyze demographic and clinical characteristics, and outcomes of patients aged 65 years and older who underwent cardiopulmonary resuscitation.

Materials and Method: Data of eldery patients who underwent cardiopulmonary resuscitaion in the emergency department between January 2013 and December 2019 were scanned retrospectively. Patients characteristics, cardiac arrest location, and outcomes were recorded and analyzed.

Results: In total, 224 patients with mean age of $76.51 \pm 8.23$ years. A return of spontaneous circulation rate was $46.4 \%$, and the 30 -day survival rate was $7.6 \%$. A return of spontaneous circulation rate was decreased with age. Some $86.7 \%$ of the patients had at least one comorbidity and cancer was the most common. The mean duration of cardiopulmonary resuscitation was $33.28 \pm 22.16$ minutes. The mean cardiopulmonary resuscitation duration in the patients who had an return of spontaneous circulation and survived was significantly lower. The $\mathrm{pH}$ and lactate values of the patients were found to be statistically different in patients who had a return of spontaneous circulation. The most common cardiac arrest cause was infectious diseases in 72 (32.1\%) patients and the most common diagnosis in living patients was cardiac causes.

Conclusion: As the number of elderly individuals increases, and the number of comorbidities increase, the number of emergency department admissions as well as the incidence of in-hospital and out-of-hospital cardiac arrest will also increase in parallel with the increase in life expectancy.

Keywords: Heart arrest; Cardiopulmonary resuscitation; Emergency service, Hospital; Aged 


\section{INTRODUCTION}

The population of elderly has been increasing globally in recent years. According to data, the elderly population aged 65 years and older constitutes $20 \%$ of the population in the USA (1). Although Turkey is composed of a comparatively young population, the increase in life expectancy worldwide is also occurring in our country. According to data from the Turkish Statistical Institute, the elderly population aged 65 years and over increased from $8.8 \%$ of the population in 2017 to $9.1 \%$ in 2019 . They predict that this percentage will reach $10.2 \%$ in $2023,20.8 \%$ in 2050 , and $27.7 \%$ in 2075 (2). Consistent with this increase, the rate of admission of elderly patients to hospitals, particularly to emergency departments (EDs) and intensive care units, is also gradually increasing (3-4).

Cardiac arrest (CA) is a leading cause of death worldwide. There are approximately 375,000-700,000 CA cases in Europe annually; in the USA, there are approximately 383,000 cases over a similar period. Internationally, the survival rate for CA is low, at $<14 \%(5-6)$. Since the introduction of external cardiac massage in 1960, cardiopulmonary resuscitation (CPR) has become the standard treatment for patients with a CA (7). The incidence of sudden CA increases markedly with age, from 100 per 100,000 in 50-year-old patients to 800 per 100,000 in 75-year-old patients (8). With the increase in the age of hospitalized patients, physicians are frequently confronted with the dilemma regarding whether resuscitation is a medically appropriate and ethically acceptable treatment for older patients (9).

We aimed to analyze demographic and clinical characteristics, and outcomes of patients aged 65 years and older undergoing CPR in the ED.

\section{MATERIALS AND METHODS}

This retrospective study was performed between January 1, 2013 and December 1, 2019 in the Department of Emergency Medicine of Cerrahpasa Faculty of Medicine, Istanbul Univercity- Cerrahpasa. The study was approved by the Ethics Committee of Cerrahpasa Faculty of Medicine, Istanbul University- Cerrahpasa (83045809-604.01.02- Date: December 3, 2019). Informed consent was not obtained, given the retrospective nature of the study.

Patients aged younger than 65 years, patients with incomplete data, and patients aged 65 years and older who were intubated but did not receive CPR were excluded from the study.

All data were collected from the hospital database. Age, sex, comorbidities, and complaints (in-hospital CA cases) of the patients were recorded. The patients were divided into three age groups: young (65-74 years), middle aged (75-84 years), and advanced age ( $\geq 85$ years). CA location was divided into in-hospital CA (IHCA) and outof-hospital CA (OHCA). Places within the hospital, such as the emergency room, outpatient clinic, and laboratories were understood to comprise the interior of the hospital. The duration of CPR and the return of spontaneous circulation (ROSC) were recorded. The final diagnoses of the patients were recorded. The patients' lactate, $\mathrm{pH}$, and partial carbon dioxide pressure values were recorded, as well as was the 30-day survival of those patients who had ROSC.

Data were analyzed using SPSS 22.0 for Windows. The Kolmogorov-Smirnov test was used for the data distribution. Descriptive statistics were applied, and the values for quantitative data were calculated as mean \pm standard deviation, whereas qualitative values were expressed as numbers and percentages. An independent sample t-test or the Mann-Whitney U-test was used to compare the means of two groups. The chi-squared test was used to compare quantitative data. A p-value $<0.05$ was considered statistically significant.

\section{RESULTS}

A total of 433 patients underwent CPR between January 1, 2013 and December 1, 2019. Some 
$52.8 \%$ (229) of the patients were aged 65 and older. Data on 5 patients were not available; thus, a total of 224 patients were included in the study. Half of the patients were women. The mean age of the patients was $76.51 \pm 8.23$ years. In-hospital CA occurred in 187 (83.5\%). The ROSC rate was $46.4 \%$ (104), and the 30 -day survival rate was $7.6 \%$ (17). The ROSC rate in the IHCA group was $48.7 \%$, while in OHCA group it was $35.1 \%$. In addition, the ROCS rate in the younger group was significantly higher than in the middle and older aged groups. Some 38.5\% (40) of the 104 patients who had
ROSC died within the first 24 hours, 29.8\% (31) died in 2-7 days, and 5.4\% (16) died in 8-30 days.

Some $86.7 \%$ (194) of the patients had at least one comorbidity. Cancer was the most common, at $34.8 \%$ (78), followed by hypertension at $33.5 \%$ (75), and diabetes at $27.7 \%$ of the patients (62). Demographic data on the patients are shown in Table 1.

The mean duration of CPR was $33.28 \pm 22.16$ minutes. The mean CPR duration in the patients who had an ROSC and survived was significantly

Table 1. Demographic data.

\begin{tabular}{|c|c|c|c|c|c|c|}
\hline & ROSC + & ROSC - & $\mathbf{p}$ & Survived & Exitus & $\mathbf{p}$ \\
\hline \multicolumn{7}{|c|}{ Age Group } \\
\hline $65-74$ & 55 & 37 & \multirow{3}{*}{$0.004^{*}$} & 11 & 81 & \multirow{3}{*}{0.120} \\
\hline $75-84$ & 33 & 54 & & 4 & 83 & \\
\hline$\geq 85$ & 16 & 29 & & 2 & 43 & \\
\hline \multicolumn{7}{|l|}{ Sex } \\
\hline Men & 49 & 63 & \multirow{2}{*}{0.421} & 6 & 106 & \multirow{2}{*}{0.313} \\
\hline Women & 55 & 57 & & 11 & 101 & \\
\hline \multicolumn{7}{|c|}{ Arrest Location } \\
\hline $\mathrm{IHCA}$ & 91 & 96 & \multirow{2}{*}{0.184} & 14 & 173 & \multirow{2}{*}{0.896} \\
\hline OHCA & 13 & 24 & & 3 & 34 & \\
\hline \multicolumn{7}{|c|}{ Comorbidities } \\
\hline Present & 94 & 100 & \multirow{2}{*}{0.177} & 15 & 179 & 0.838 \\
\hline Absent & 10 & 20 & & 2 & 28 & \\
\hline Cancer & 35 & 43 & 0.783 & 3 & 75 & 0.200 \\
\hline HT & 44 & 31 & 0.009 & 8 & 67 & 0.334 \\
\hline DM & 33 & 29 & 0.207 & 6 & 56 & 0.573 \\
\hline CAD & 23 & 20 & 0.302 & 7 & 36 & 0.025 \\
\hline $\mathrm{HF}$ & 19 & 15 & 0.230 & 4 & 30 & 0.300 \\
\hline COPD & 10 & 7 & 0.286 & 1 & 16 & 1 \\
\hline CVD & 7 & 10 & 0.842 & 0 & 17 & 0.375 \\
\hline CRF & 7 & 7 & 0.782 & 2 & 12 & 0.288 \\
\hline Alzheimer & 8 & 5 & 0.260 & 1 & 12 & 1 \\
\hline
\end{tabular}

*, Diffenrence between 65-74 and 75-84, $\geq 85$ age group

ROSC, return of spontaneous circulation; OHCA, Out-of-hospital cardiac arrest; IHCA, In- hospital cardiac arrest; HT, hypertension; DM, diabetes mellitus; $\mathrm{CAD}$, coronary artery disease; HF, heart failure; COPD, chronic obstructive pulmonary disease; CVD, cerebrovascular disease; CRF, chronic renal failure. 
lower. The mean age of the women was significantly higher, and the mean age of the patients who had an ROSC was significantly lower (Table 2).

When the complaints from the IHCA patients were analyzed, dyspnea was the most common, at $50.6 \%$ (91), followed by nausea/vomiting, abdominal pain, and syncope (Figure 1).

The $\mathrm{pH}$ and lactate values of the patients were found to be statistically different in patients with successful resuscitation. There was no difference in 30-day survival between blood parameters common diagnosis in living patients was cardiac causes in 10 patients (Figure 3 ).

\section{DISCUSSION}

Improvements in living conditions and healthcare in developed countries have resulted in increased life expectancy and duration; therefore, the number of elderly individuals presenting at hospitals and emergency services is also increasing. The rates of admission to EDs according to the sex of elderly

Table 2. Comparison of mean age and CPR duration.

\begin{tabular}{|c|c|c|c|c|c|c|}
\hline & Age in years & & $\mathbf{p}$ & CPR duration & nutes & p \\
\hline \multirow{2}{*}{$\begin{array}{l}\text { ROSC } \\
(n, \%)\end{array}$} & Yes & No & \multirow[b]{2}{*}{0.016} & Yes & No & \multirow[b]{2}{*}{0.000} \\
\hline & $\begin{array}{l}75.10 \pm 8.55(104 \\
46.4 \%)\end{array}$ & $\begin{array}{l}77.74 \pm 7.77(120 \\
53.6 \%)\end{array}$ & & $15.95 \pm 12.59$ & $48.30 \pm 17.52$ & \\
\hline \multirow{2}{*}{$\begin{array}{l}\text { Sex } \\
(n, \%)\end{array}$} & Men & Women & \multirow[b]{2}{*}{0.000} & Men & Women & \multirow[b]{2}{*}{0.18} \\
\hline & $\begin{array}{l}74.46 \pm 7.40(112 \\
50 \%)\end{array}$ & $\begin{array}{l}78.56 \pm 8.54(112 \\
50 \%)\end{array}$ & & $35.25 \pm 21.51$ & $31.31 \pm 22.71$ & \\
\hline \multirow[b]{2}{*}{$\begin{array}{l}\text { 30-day survival } \\
(n, \%)\end{array}$} & Survived & Exitus & \multirow[b]{2}{*}{0.113} & Survived & Exitus & \multirow[b]{2}{*}{0.000} \\
\hline & $\begin{array}{l}73.47 \pm 7.67(17 \\
7.6 \%)\end{array}$ & $\begin{array}{l}76.76 \pm 8.24(207 \\
92.4 \%)\end{array}$ & & $14.53 \pm 12.22$ & $34.82 \pm 22.10$ & \\
\hline \multirow[b]{2}{*}{$\begin{array}{l}\text { Arrest location } \\
(n, \%)\end{array}$} & IHCA & OHCA & \multirow[b]{2}{*}{0.761} & IHCA & OHCA & \multirow[b]{2}{*}{0.086} \\
\hline & $\begin{array}{l}76.14 \pm 8.25(187 \\
83.5 \%)\end{array}$ & $\begin{array}{l}76.59 \pm 8.25(37 \\
16.5 \%)\end{array}$ & & $32.15 \pm 21.93$ & $39.00 \pm 22.74$ & \\
\hline
\end{tabular}

ROSC, return of spontaneous circulation; OHCA, Out-of-hospital cardiac arrest; IHCA, In-hospital cardiac arrest.

(Figure 2).

When the definitive diagnoses of patients with CA were examined according to cause, the most common causes were infectious diseases in $72(32.1 \%)$ patients, cardiac causes in $66(29.5 \%)$, and respiratory causes in 43 (19.2\%). The most patients generally differ by country (10-12). In our study, the proportions of men and women were equal.

The incidence of at least one comorbidity in elderly patients is 70\%-83\%, and hypertension, coronary artery disease, diabetes mellitus, chronic 
Figure 1. Distribution of the complaints of patients with IHCA.

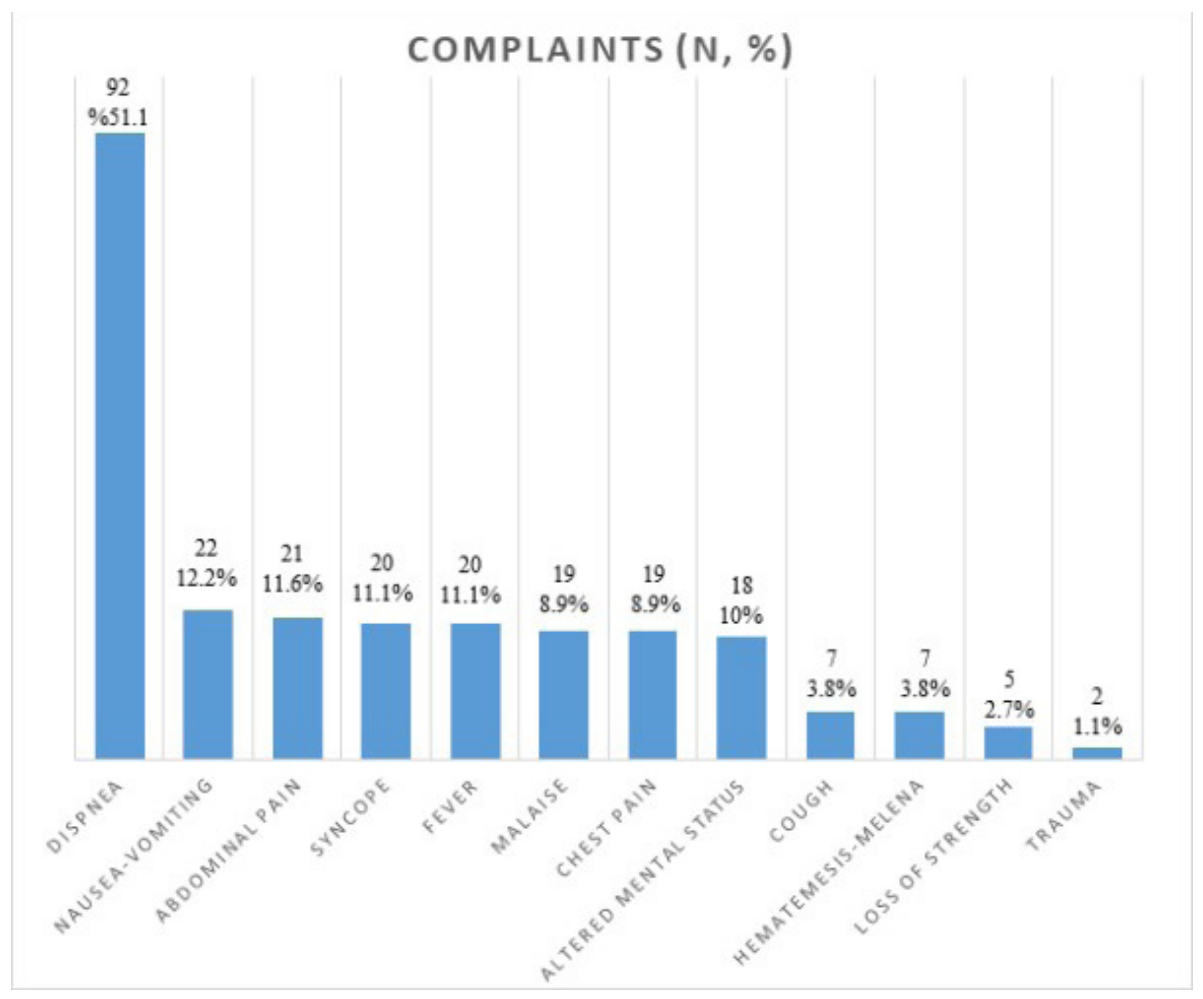

heart failure, and chronic obstructive pulmonary disease are among the most common comorbidities (13-15). In our study, the comorbidity rate was higher than that of the other studies. Cancer was found to be the most common comorbidity, probably because our hospital is a leading hospital to monitor and treat oncological cases, especially in our region. This situation reflects higher cancer rates in the elderly population along with other comorbidities due to increased life expectancy, and might be found in EDs in CAs that develop as a result of complications related to cancer.

Socioeconomic status and comorbidity did not directly affect the outcome after CA in patients younger than 65 years of age, whereas increasing age and number of comorbidities had negatively affected ROSC and hospital survival in elderly patients (16-18). Even if there was no significant relationship between the presence of comorbidity, ROSC, and 30-day survival, except in terms of a history of hypertension in our study, higher comorbidity rates in elderly patients could be associated with a lower ROSC rate.

It is known that ROSC and survival rates are poorer in elderly patients in CA conditions inhospital or out-of-hospital (12). The ROSC rate was between $7.7 \%$ and $48.2 \%$ in the lower age group, and was between $4.5 \%$ and $20 \%$ in the patients older than 85 years of age. However, the 30 day survival or hospital discharge rate of elderly patients decreased with age: it was between 5.2\% and $20 \%$ in the younger age group and between $1.9 \%$ and $3.9 \%$ in the older age group. Despite low ROSC and survival rates in elderly patients, 12-month survival and favorable neurological outcome rates of the elderly patients who were 
discharged from the hospital were 87\%-92\% (19-21). In our study, older individuals had lower ROSC and 30-day survival rates compared with their younger counterparts. Of the 17 survivors, 15 (88.2\%) were still alive in the short-term follow up.

It has been reported that CPR duration was shorter in patients who had ROSC or survived. Also, the ROSC and survival rates were higher in patients with a shockable rhythm or an arrhythmia $(12,22-23)$, a finding consistent with the literature. We also believe that more than half of our surviving patients had CA due to cardiac causes, which might have included shockable rhythms and arrhythmias.

Dyspnea, abdominal pain, chest pain, fever, general malaise, and limb pain were the most common complaints of elderly patients at ED admission (9). In our study, dyspnea was the most common symptom in patients with CA. Myocardial infarction, arrhythmia, heart failure, and lung edema were common causes of CA in elderly patients, followed by respiratory, metabolic, and neurological causes $(11,13,21)$. Even if cardiac and respiratory causes were common in our study, infectious causes were the top cause of CA. This situation could be related to the spread of infectious diseases in the winter season and complication of cancer related therapy.

Low $\mathrm{pH}$ values and high lactate levels were found to be associated with mortality. In addition, the mortality rate was found to be as high as $100 \%$, especially in patients with $\mathrm{pH}$ values under 7.1 (24-25). In our study, high lactate levels and low $\mathrm{pH}$ values were significantly associated with unsuccessful CPR, however they had no effect on survival.

This study has some limitations. First, we were not able to perfom a rhythm analysis of all patients before or during CA because of OHCA cases. Second, we were not able the determine

Figure 2. Comparison of the blood gas parameters in ROSC and 30-day survival.
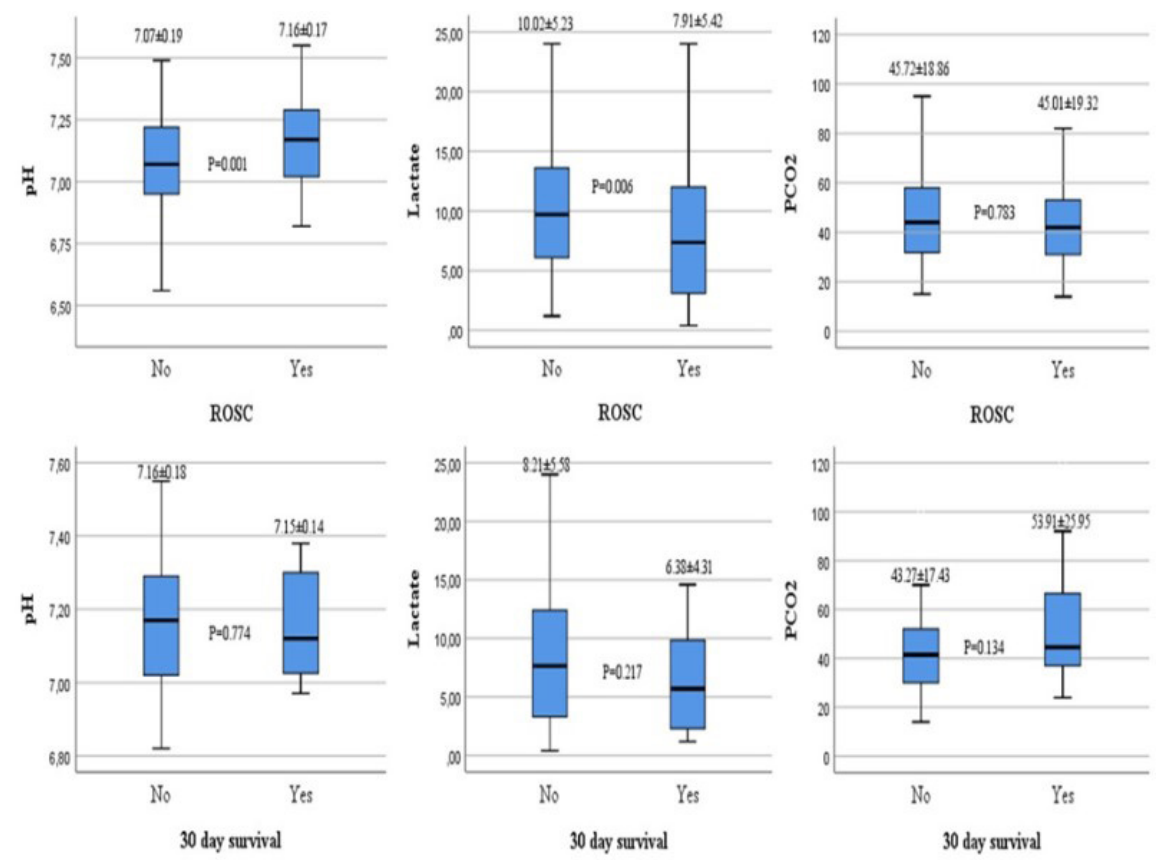
Figure 3. Distribution of the causes of cardiac arrest.

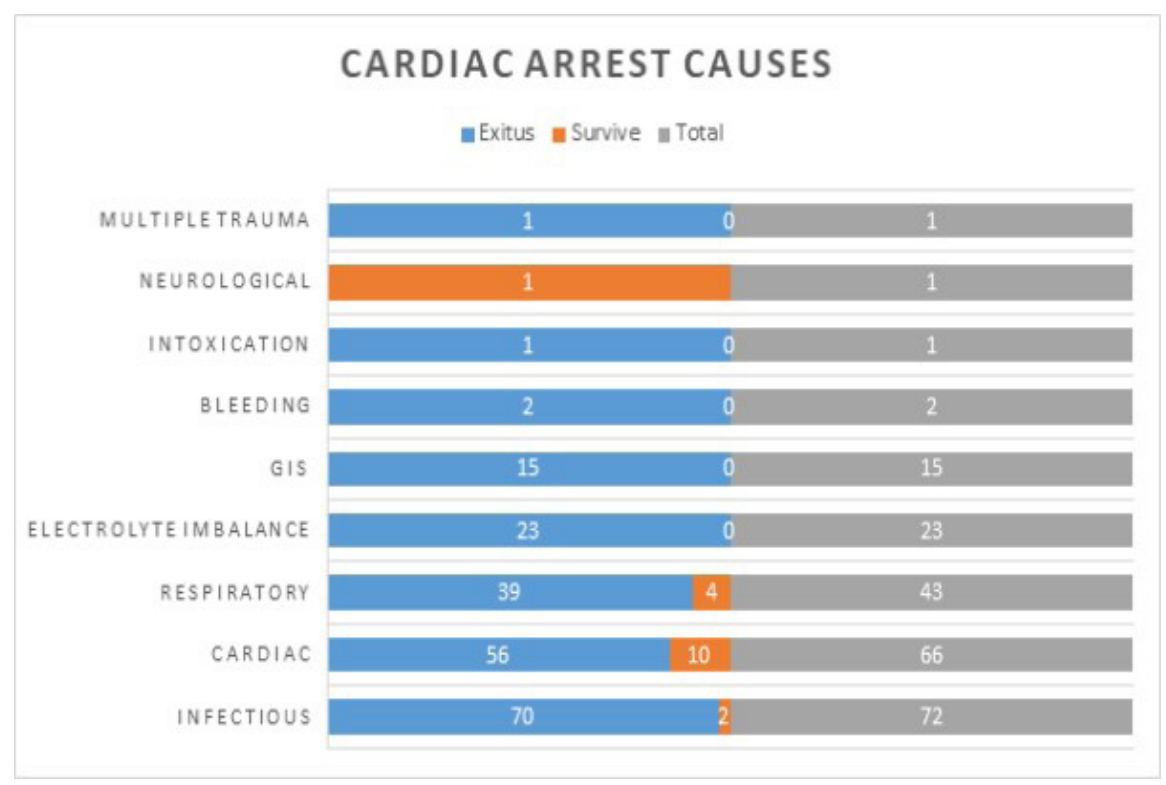

the CPR duration of the patients with OHCA. Third, long-term follow up and an assessment of detailed neurological outcomes, such as cerebral performance category scale, were not performed in our study.

In conclusion, in parallel with the increase in life expectancy, an increase in the number of elderly individuals is inevitable. As the number of elderly individuals increases, the number of ED admissions as well as the incidence of IHCA and
OHCA will also increase. As age and the number of comorbidities increase in elderly patients, ROSC rates decrease, as does the chance of survival in these patients. However, considering the high rate of favorable neurological outcomes in patients who are discharged from the hospital, further studies should be conducted to determine factors that might increase the survival rates of these patients after resuscitation.

\section{REFERENCES}

1. The Population 65 Years and Older in the United States: 2016 [Internet] Available from: https:// www.census.gov/content/dam/Census/library/ publications/2018/acs/ACS-38.pdf. Accessed: 22.04.2020.

2. Türkiye İstatistik Kurumu [Internet] Available from: http://www.tuik.gov.tr/UstMenu.do?metod=temelist. Accessed: 12.03.2020.

3. Samaras N, Chevalley T, Samaras D, Gold G. Older

patients in the emergency department: a review. Ann Emerg Med 2010;56(3):261-9. (PMID:20619500).

4. Demircan A, Aygencel Bıkmaz ŞG, Kadı G, et al. Evaluation of the general characteristics of patients aged 85 years and above admitted to a university hospital emergency department. Turk J Med Sci 2017;47:1393-1402. (PMID:29151309).

5. Haydon G, Van der Riet P, Maguire J. Survivors' quality of life after cardiopulmonary resuscitation: an 
integrative review of the literature. Scand J Caring Sci 2017;31:6-26. (PMID:27440375)

6. Sasson C, Rogers MA, Dahl J, Kellermann AL. Predictors of survival from out-of-hospital cardiac arrest: a systematic review and metaanalysis. Circ Cardiovasc Qual Outcomes 2010;3:63-81. (PMID:20123673)

7. Kouwenhoven WB, Jude JR, Knickerbocker GG. Closed-chest cardiac massage. JAMA 1960;173:10647. (PMID:14411374).

8. Becker LB, Han BH, Meyer PM, et al. Racial differences in the incidence of cardiac arrest and subsequent survival. The CPR Chicago project. N Engl J Med 1993;329:600-6. (PMID:8341333).

9. van Gijn MS, Frijns D, van de Glind EM, C van Munster B, Hamaker ME. The chance of survival and the functional outcome after in-hospital cardiopulmonary resuscitation in older people: a systematic review. Age Ageing 2014;43:456-463. (PMID: 24760957).

10. Bedel C, Tomruk Ö. Characteristics of geriatric patients presenting to an emergency department of a university hospital. Med J SDU 2018;25(4):393-399. DOI:10.17343/sdutfd.370472

11. Hirlekar G, Karlsson T, Aune $\mathrm{S}$, et al. Survival and neurological outcome in the elderly after in-hospital cardiac arrest. Resuscitation 2017;118:101-106. (PMID:28736324).

12. Sulzgruber P, Sterz F, Poppe M, et al. Age-specific prognostication after out-of-hospital cardiac arrest - the ethical dilemma between 'life-sustaining treatment' and 'the right to die' in the elderly. Eur Heart J Acute Cardiovasc Care 2017;6(2):112-120. (PMID:27669729).

13. Karaveli A, Cerit GN, Özyurt E. Evaluation of admission causes and mortality rates of 65 years of age and older patients admitted from the emergency department to the intensive care unit. Turkish Journal of Geriatrics 2018;21(4):515-521. DOI: 10.31086/ tjgeri.2018.56

14. Schwartz BC, Jayaraman D, Warshawsky PJ. Survival from in-hospital cardiac arrest on the internal medicine clinical teaching unit. Can J Cardiol 2013;29:117-121. (PMID:22640493).

15. Fuchs L, Chronaki CE, Park S, et al. ICU admission characteristics and mortality rates among elderly and very elderly patients. Intensive Care Med 2012;38(10):1654-61. (PMID:22797350).

16. Uray T, Mayr FB, Fitzgibbon J, et al. Socioeconomic factors associated with outcome after cardiac arrest in patients under the age of 65. Resuscitation 2015;93:14-19. (PMID:29216950).

17. Andrewa E, Nehmea Z, Bernarda S, Smitha K. The influence of comorbidity on survival and longterm outcomes after out-of-hospital cardiac arrest. Resuscitation 2017;110:42-47. (PMID:27816529).

18. Terman SW, Shields TA, Hume B, Silbergleit R. The influence of age and chronic medical conditions on neurological outcomes in out of hospital cardiac arrest. Resuscitation 2015;89:169-176. (PMID:25640799).

19. Jensen MW, Kjaergaard J, Hassager C, et al. Resuscitation and post resuscitation care of the very old after out-of-hospital cardiac arrest is worthwhile. Int J Cardiol 2015;201:616-623. (PMID:26340128).

20. Andrew E, Mercier E, Nehme Z, Bernard S, Smith K. Long-term functional recovery and health-related quality of life of elderly out-of-hospital cardiac arrest survivors Resuscitation 2018;126:118-124. (PMID:29545136).

21. Matsuyamaa T, Kitamurab T, Kiyoharac K, et al. Assessment of the 11-year nationwide trend of out-ofhospital cardiac arrest cases among elderly patients in Japan (2005-2015). Resuscitation 2018;131:83-90. (PMID:30099119).

22. Segal N, di Pompeo C, Escutnaire J, et al. Evolution of survival in cardiac arrest with age in elderly patients:is resuscitation a dead end? J Emerg Med 2018;54(3):295-301. (PMID:29273461).

23. Roedla K, Jarczaka D, Beckerc S, Fuhrmanna V, Klugea S, Müllera J. Long-term neurological outcomes in patients aged over 90 years who are admitted to the intensive care unit following cardiac arrest. Resuscitation 2018;132;6-12. (PMID:30144464).

24. Dinkci MD, Yüce $Y$, Çevik B, Erkal KH. Retrospective analysis of factors affecting intensive care unit mortality in patients over 75 years of age. Turkish Journal of Geriatrics 2017;20(2):91-99.

25. Haas SA, Lange T, Saugel B, Petzoldt M, Fuhrmann $V$, Metschke $M$, et al. Severe hyperlactatemia, lactate clearance and mortality in unselected critically ill patients. Intensive Care Med 2016;42:202-10. (PMID:26556617). 